\title{
Traditional Chinese herbal formula relieves snoring by modulating activities of upper airway related nerves in aged rats
}

This article was published in the following Dove Press journal: Drug Design, Development and Therapy

\author{
Kou-Toung Chung* \\ Chih-Hsiang Hsu* \\ Ching-Lung Lin \\ Sheue-Er Wang \\ Chung-Hsin Wu
}

Department of Life Science, National

Taiwan Normal University, Taipei,

Taiwan

*These authors contributed equally to this work
Correspondence: Chung-Hsin Wu Department of Life Science, National Taiwan Normal University, 88, Sec 4, Ting-Chou Road, Taipei I 1677, Taiwan Tel +8862 77346363

$\mathrm{Fax}+886229312904$

Email megawu@ntnu.edu.tw
Aim: The present study investigated whether intraperitoneal treatment with the herbal formula B210 ([B210]; a herbal composition of Gastrodia elata and Cinnamomum cassia) can reduce snoring in aged rats. Also, we studied possible neural mechanisms involved in B210 treatment and subsequent reduced snoring in rats.

Methods and result: We compared pressure and frequency of snoring, activities of phrenic nerve (PNA), activities of recurrent laryngeal nerve (RLNA) and activities of hypoglossal nerve (HNA), inspiratory time $\left(\mathrm{T}_{\mathrm{I}}\right)$ and expiratory time $\left(\mathrm{T}_{\mathrm{E}}\right)$ of PNA, and pre-inspiratory time (Pre- $\left.\mathrm{T}_{\mathrm{I}}\right)$ of HNA in aged rats between sham and B210 treatment groups ( $30 \mathrm{mg} / \mathrm{mL}$ dissolved in DMSO). We found that aged rats that received B210 treatment had significantly reduced pressure and frequency of snoring than rats who received sham treatment. Also, we observed that aged rats that received B210 treatment had significantly increased PNA, RLNA, and HNA, extended T and $T_{E}$ of PNA, and prolonged Pre- $T_{I}$ of HNA compared to rats that received sham treatment. In other words, B210 treatment may relieve snoring through modulating activities and breathing time of upper airway related nerves in aged rats.

Conclusion: We suggested that the B210 might be a potential herbal formula for snoring remission.

Keywords: Chinese herbal medicine, snoring remission, upper airway, phrenic nerve, recurrent laryngeal nerve, hypoglossal nerve

\section{Introduction}

Sleep disordered breathing such as serious snoring and sleep apnea is common in aging. ${ }^{1}$ Snoring is a sign of resistance to the passage of air into the lungs and also a sign of breathing problems. ${ }^{2}$ Many studies have reported that sleep disordered breathing, such as snoring, was connected with many causes of death such as hypertension, myocardial infarction, and stroke. ${ }^{3-5}$ Electrical stimulation of the upper airway dilator muscles to reduce snoring has been used for many years, however, most people do not want intrusive surgery. ${ }^{6}$ Allover the world, including Taiwan, many patients with serious snoring are unwilling to use continuous positive airway pressure and to undergo surgery. Thus, seeking a potential traditional Chinese medicine as an alternative treatment may be another option for the treatment of serious snoring. ${ }^{7}$ In Taiwan, the herbal formula B210 ([B210]; a herbal composition of Gastrodia elata and Cinnamomum cassia) is a well-known, patented Chinese herbal formula (patent no 361075 issued by Intellectual Property Office of Taiwan; patent owner: Brion Research Institute of Taiwan) for patients with sleep disorders to reduce snoring. However, the possible neural mechanism concerning pharmacological 
effects of B210 in snoring remission is still unclear. The causes of snoring are multi-factorial, involving the complex interplay between the central and peripheral nervous system, respiratory related nerves such as phrenic nerve, and upper airway related nerves such as recurrent laryngeal and hypoglossal nerves, and their neurotransmitters, all of which play a role in snoring. ${ }^{8}$

In this study, we aimed to investigate whether a traditional Chinese herbal formula such as B210, may relieve snoring through modulating activities of the respiratory related phrenic nerve, and upper airway related nerves such as recurrent laryngeal and hypoglossal nerves in aged rats. To achieve our research goals, we designed a snoring rat model, as described in previous studies. ${ }^{9-12}$ First, we confirmed whether intraperitoneal B210 treatment could reduce snoring in these rats. Then, the activities of phrenic nerve (PNA), activities of recurrent laryngeal nerve (RLNA), and activities of hypoglossal nerve (HNA) of the snoring rat model were recorded and compared before and after intraperitoneal B210 treatment. Also, the PNA, RLNA, and HNA of the snoring rat model were compared between sham and B210 treatment groups. This is the first study to utilize neurophysiological methods to clarify the therapeutic mechanism of B210 for snoring remission in a snoring rat model. Our study reveals that B210 might be a potential herbal formula for snoring remission.

\section{Materials and methods Chromatographic fingerprint analysis of $B 210$}

B210 (Taiwan patent no 361075) was provided free of charge by Brion Research Institute of Taiwan. High performance liquid chromatography (HPLC) fingerprints of individual herbal extracts and the combination of individual herbal extracts were generated to monitor the presence or absence of individual herbs of B210 (Figure 1). HPLC grade acetonitrile was purchased from Burdick \& Jackson (Gyeonggi-do, Korea), along with methanol from Avantor (Center Valley, PA, USA). All the chemicals used were of analytical grade and solubilized in distilled $\mathrm{H}_{2} \mathrm{O} / \mathrm{MeOH}$. The combined extracts were dried and re-dissolved in $2 \mathrm{~mL}$ of $50 \%$ methanol. The prescription of the herbal formula B210 mainly contains two kinds of medicinal herbs, G. elata and C. cassia, in specific ratios. A total of $10 \mathrm{~mL}$ of B210 was injected into the HPLC system. For the analysis of every single herbal extract, an amount of extract of that herb equivalent to the amount of $50 \mathrm{mg}$ of extract was prepared based on its yield, and analyzed using the method described previously. All samples were analyzed in triplicate.

\section{The $\mathrm{IC}_{50}$ of $\mathrm{B} 2 \mathrm{IO}$}

The half maximal inhibitory concentration $\left(\mathrm{IC}_{50}\right)$ of B210 was evaluated by MTT assay. SH-SY5Y cells were plated at $37^{\circ} \mathrm{C}$
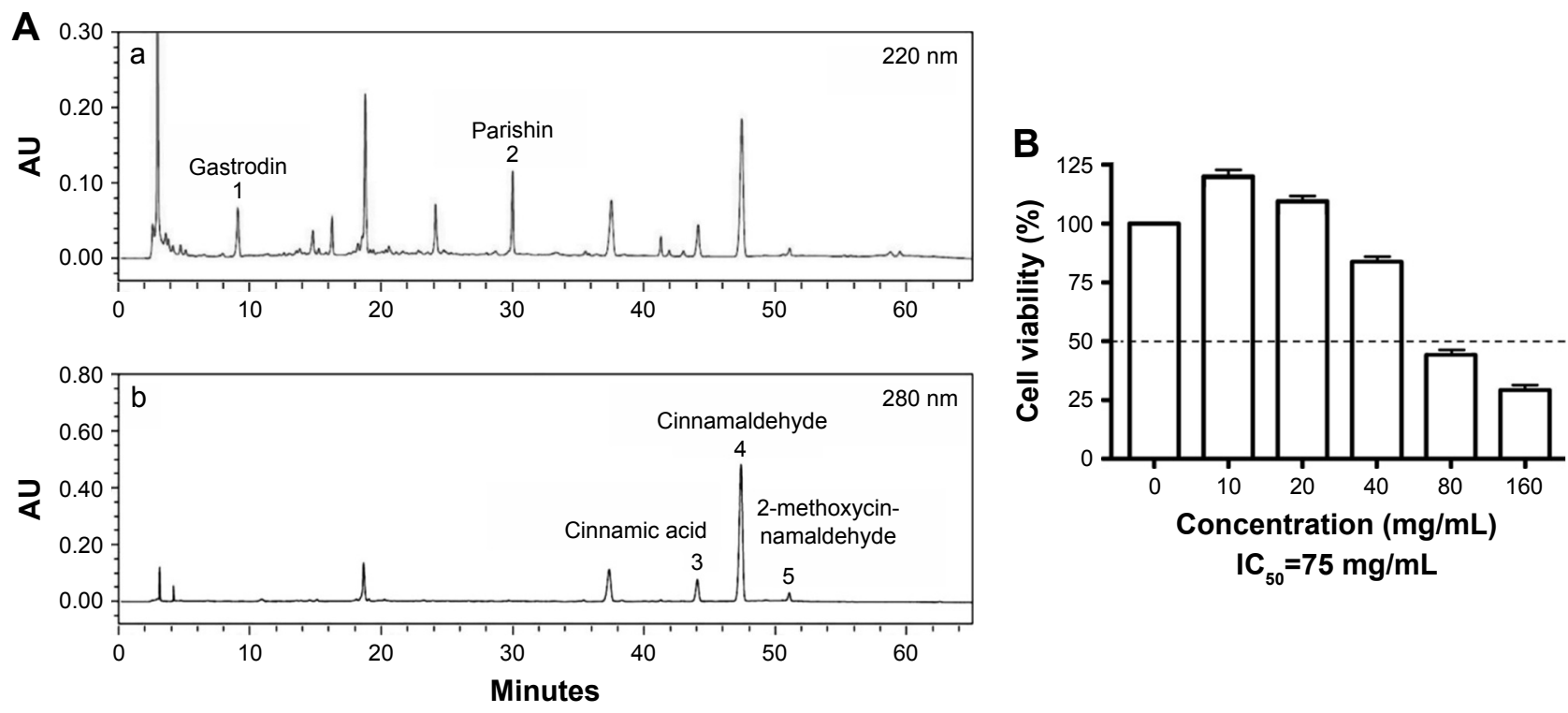

Figure I Chromatographic fingerprint analysis and cell viability assay for the B2I0.

Notes: (A) HPLC fingerprint of the B210. Characteristic peaks of the B210, ie, (a) gastrodin (peak I) and parishin (peak 2) (from Gastrodia elata), (b) cinnamic acid (peak 3), cinnamaldehyde (peak 4), and 2-methoxycinnamaldehyde (peak 5) (from Cinnamomum cassia) were identified and marked at the corresponding peaks in the fingerprint. (B) Cell viabilities of RA-induced SH-SY5Y cells in the absence or presence of B210 at indicated doses. The $1 \mathrm{C}_{50}$ of $\mathrm{B} 210$ is $75 \mathrm{mg} / \mathrm{mL}$, which represents the concentration of $\mathrm{B} 2 \mathrm{I} 0$ that is required for $50 \%$ inhibition in vitro.

Abbreviations: AU, arbitrary unit; B2 I0, herbal formula B210; HPLC, high performance liquid chromatography; IC ${ }_{50}$, half maximal inhibitory concentration; RA, retinoic acid. 
with $5 \% \mathrm{CO}_{2}$ for 24 hours. Then, SH-SY5Y cells were treated with B210 (10-160 mg/mL dissolved in DMSO) for 24 hours to determine the $\mathrm{IC}_{50}$ of cytotoxicity. After incubation with $100 \mu \mathrm{L}$ of MTT solution $(0.5 \mathrm{mg} / \mathrm{mL})$ at $37^{\circ} \mathrm{C}$ for 3 hours, $100 \mu \mathrm{L}$ of $10 \%$ sodium dodecyl sulfate- $0.01 \mathrm{~N} \mathrm{HCl}$ solution was added to each well and incubated at $37^{\circ} \mathrm{C}$ overnight to dissolve the formazan. The absorbency was measured at $570 \mathrm{~nm}$ with an ELISA reader (uQuant, BioTek Instruments Inc., Winooski, VT, USA), and the results were expressed as the relative cell viability of treated cells against those of the controls.

\section{Animal preparation}

Twenty-two aged male Wistar rats of 30-36 months old (486 $\pm 19 \mathrm{~g}$ ) were used in this study. All rats were housed in a room kept at $25^{\circ} \mathrm{C}$ with access to water and food ad libitum. Experiments were performed with the consent of the Animal Care and Use Committee of National Taiwan Normal University (NTNU-ACUC-101017) under the guidelines of Taiwan Animal Protection Law for the welfare of animals. The research involves animal experiments and has considered the $3 \mathrm{R}$ rules of Replace, Reduce, and Refine to optimize the experimental design.

Before experiment recording, aged rats were weighed and treated with atropine $(0.5 \mathrm{mg} / \mathrm{Kg}$, intramuscular injection) to reduce bronchial secretion. After 30 minutes, the animals were anesthetized with urethane (1.2 g/Kg, intraperitoneal injection). Tracheal and vascular intubations were applied for spontaneous breathing. Then, the blood pressure was measured and the saline was administered by way of these intubations. The end-tidal fractional concentration of $\mathrm{CO}_{2}$ was continuously monitored with $\mathrm{C} \mathrm{CO}_{2}$ analyzer (Model CD-3A carbon dioxide analyzer, AEI Technologies, Inc., Pittsburgh, PA, USA). The body temperature was maintained at $37^{\circ} \mathrm{C}-38^{\circ} \mathrm{C}$ with a heat blanket or lamp. In this study, six rats were used for snoring assessment, eight rats were used for neural activity recording of PNA and RLNA, and seven rats were used for recording of PNA and HNA. Data of the experimental groups were obtained from aged rats that received intraperitoneal B210 treatment. Preparation method for $\mathrm{B} 210$ was $30 \mathrm{mg} / \mathrm{mL}$ dissolved in DMSO. The dosage of B210 was $150 \mathrm{mg} / \mathrm{Kg}$ for each intraperitoneal treatment. Preparation method for sham treatment was used with the DMSO injection volume of $5 \mathrm{~mL} / \mathrm{Kg}$.

\section{Snoring assessment}

Snoring pressure and frequency of anesthetized rats was assessed before and after intraperitoneal B210 treatment (30 $\mathrm{mg} / \mathrm{mL}$ dissolved in DMSO; the $\mathrm{pH}$ value was close to 7.0). As described in the Introduction section, we designed a snoring rat model as described in previous studies. ${ }^{9-12}$
Snoring pressure and frequency in the anesthetized rats was measured in a supine position. Partial upper airway obstruction and snoring were produced via external compression of the pharynx with a miniature sandbag. Sound pressure $\left(\mathrm{P}_{\text {SOUND }}\right)$ and sound frequency $\left(\mathrm{F}_{\text {SOUND }}\right)$ were measured by using a cardioid polar pattern studio condenser microphone (CAD M37, CAD Professional Microphones, Menton, $\mathrm{OH}$, USA) positioned at $30^{\circ}$ to the vertical and at a distance of $1.5 \mathrm{~cm}$ from the rat's mouth. The microphone has a frequency response of $20 \mathrm{~Hz}-20 \mathrm{kHz}$ and operates linearly between $50 \mathrm{~Hz}$ and $3 \mathrm{kHz}$ with a manufacturer-specified sensitivity. The microphone was interfaced with a preamplifier (Symetrix SX202, Symetrix, Mountlake Terrace, WA, USA), providing the signal with a gain of $55 \mathrm{~dB}$. In this study, snoring was induced via compression of the pharyngeal tissues by using a miniature sandbag (weighing $10.0 \mathrm{~g}$ ) placed on the skin of the neck just above the larynx, forcing partial obstruction of the pharynx. In this study, we kept a constant pressure on the neck of rats before and after intraperitoneal B210 treatment.

\section{Recording of PNA, RLNA, and HNA}

The phrenic nerve of the anesthetized rat was isolated via a dorsolateral approach at the spinal level of C4-C5 and cut peripherally. The recurrent laryngeal nerve of the anesthetized rat was dissected along the trachea on the right side and was cut distally. The hypoglossal nerve of the anesthetized rat on the left side was separated via a ventral approach and cut distally. Then the PNA, RLNA, and HNA of rats were continuously recorded before and after intraperitoneal sham or B210 treatment for at least 30 minutes. The PNA, RLNA, and HNA were monitored by a bipolar electrode, amplified by a differential amplifier (Grass P511 AC amplifier, Grass Instruments Co., West Warwick, RI, USA), filtered $(0.3-3 \mathrm{kHz})$, and integrated by a homemade integrator (time constant $=0.02 \mathrm{~s}$ ). Neural signals were displayed on a digital oscilloscope (Tektronix TDS420A Oscilloscope, Tektronix, Inc., Beaverton, OR, USA) and stored simultaneously on the hard disc via the PowerLab system (ADI Instrument, Colorado Springs, CO, USA).

\section{Statistical analysis of data}

Data were retrieved and analyzed by software written in the Visual $\mathrm{C}^{++}$language. Neural discharges of 20 respiratory cycles before and after 30 minutes of sham treatment were computed and averaged as the negative control group and positive control group, respectively. The rats that received sham treatment were treated with intraperitoneal solvent. Neural discharges of 20 respiratory cycles before and after 30 minutes of intraperitoneal B210 treatment were computed 
and averaged as the no-treatment control group and the experimental group, respectively. For the purpose of uniform comparison, the pressure $\left(\mathrm{P}_{\text {SOUND }}\right)$ and frequency $\left(\mathrm{F}_{\text {SOUND }}\right)$ of snoring, and the PNA, RLNA, and HNA after 30 minutes of intraperitoneal B210 treatment were taken as experimental data, which were further transformed into percentage of pretreatment data, while real inspiratory time $\left(\mathrm{T}_{\mathrm{I}}\right)$, expiratory time $\left(\mathrm{T}_{\mathrm{E}}\right)$, and pre-inspiratory time (Pre- $\mathrm{T}_{\mathrm{I}}$ ) of aged rats were obtained from the neurograms of PNA and HNA individually. We quantified and then compared the relative PNA, RLNA, HNA, and real $T_{I}, T_{E}$, and Pre- $T_{I}$ in rats that received sham and B210 treatments by Student's $t$-test. All values were expressed as mean \pm standard error of the mean (SEM). $P$-values of at least $<0.05$ were considered significant.

\section{Results}

\section{Characterization of B210}

HPLC fingerprints showed that the combination of individual herbal extracts had a pattern consistent with that of the standard product. By comparing the on-line ultraviolet spectra and retention times, peaks in the standard product with those of the individual herbal extracts, this showed that active ingredients of B210 such as gastrodin (formula: $\mathrm{C}_{13} \mathrm{H}_{18} \mathrm{O}_{7}$; molecular weight [MW]: $286.27 \mathrm{~g} / \mathrm{mol}$ ) and parishin (formula: $\mathrm{C}_{45} \mathrm{H}_{56} \mathrm{O}_{25}$; MW: $996.92 \mathrm{~g} / \mathrm{mol}$ ) from G. elata, cinnamic (formula: $\mathrm{C}_{9} \mathrm{H}_{8} \mathrm{O}_{2}$; $\mathrm{MW}: 148.16 \mathrm{~g} / \mathrm{mol}$ ), cinnamaldehyde (formula: $\mathrm{C}_{9} \mathrm{H}_{8} \mathrm{O} ; \mathrm{MW}: 132.16 \mathrm{~g} / \mathrm{mol}$ ), and 2-methoxycinnamaldehyde (formula: $\mathrm{C}_{10} \mathrm{H}_{10} \mathrm{O}_{2} ; \mathrm{MW}$ : $162.19 \mathrm{~g} / \mathrm{mol}$ ) from C. cassia were identified and marked at the corresponding peaks in the fingerprint (Figure 1A). As detected by MTT assay, the $\mathrm{IC}_{50}$ of B210 is $75 \mathrm{mg} / \mathrm{mL}$, which represents the concentration of B210 that is required for $50 \%$ inhibition in vitro (Figure 1B).

\section{Effects of the B2 10 treatment on snoring of aged rats}

An example of the $\mathrm{P}_{\text {SOUND }}$ and $\mathrm{F}_{\text {SOUND }}$ of snoring of a rat before and after 30 minutes of intraperitoneal B210 treatment is
A a

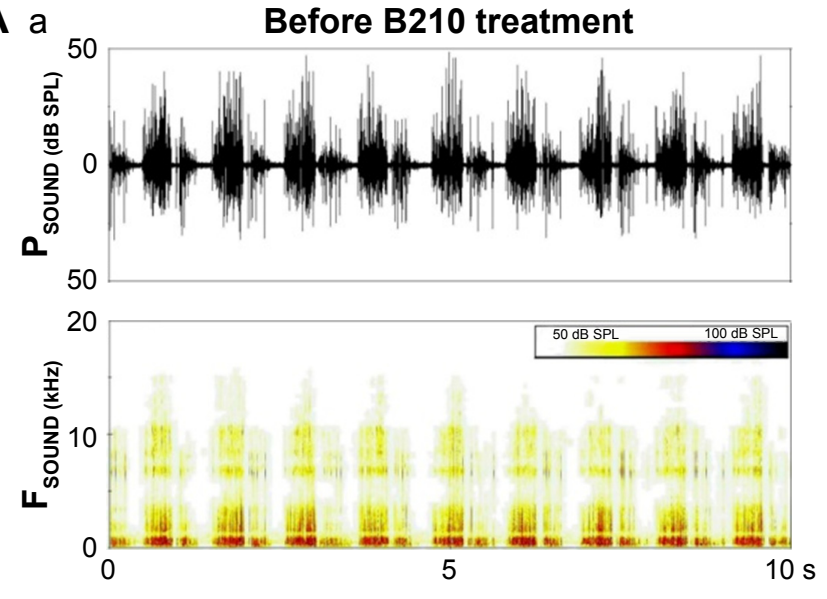

B a

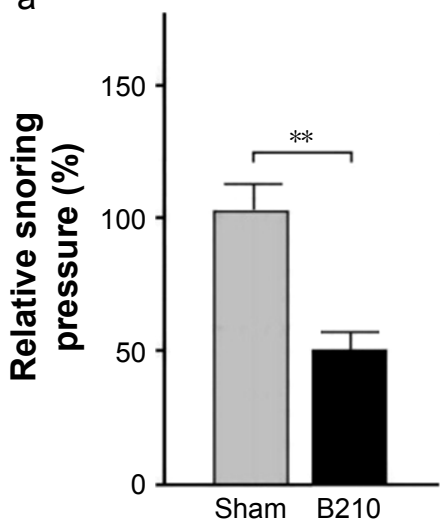

b
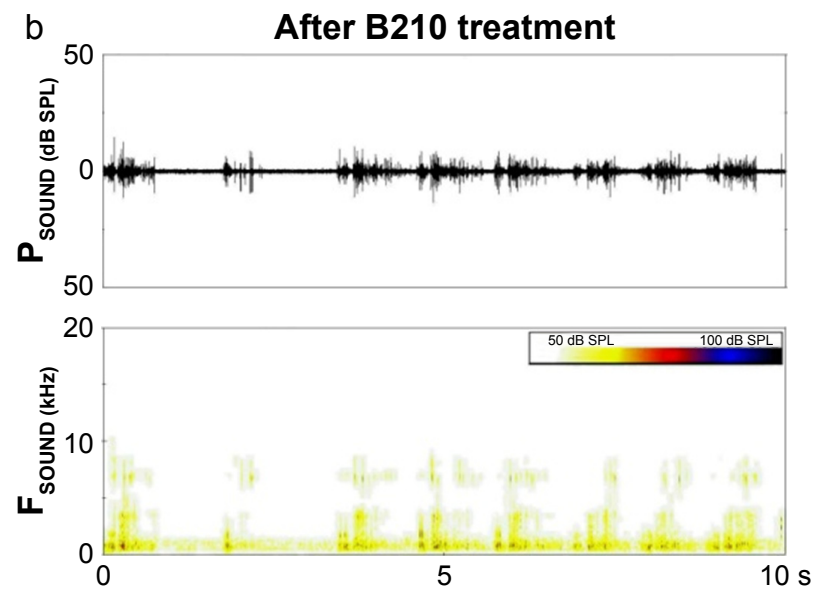

b

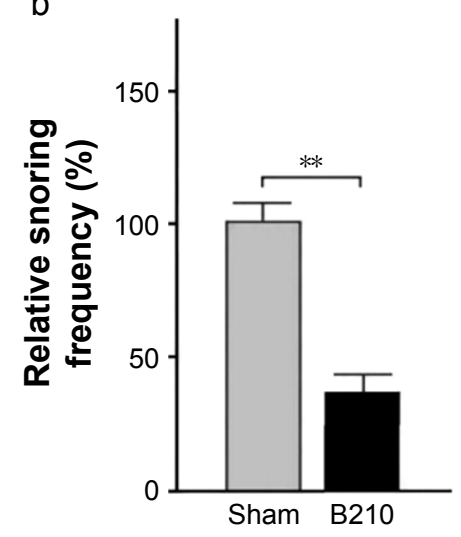

Figure 2 B210 treatment obviously reduced snoring pressure and frequency in the snoring rat model.

Notes: $(A)$ Example of sound pressure $\left(P_{\text {sound }}\right)$ and sound frequency $\left(F_{\text {sound }}\right)$ of snoring in a rat before $(a)$ and after 30 minutes of intraperitoneal $B 210$ treatment $(b)$. (B) Quantified relative $\mathrm{P}_{\text {SOUND }}(\mathrm{a})$ and $\mathrm{F}_{\text {SOUND }}(\mathrm{b})$ of rats with sham and intraperitoneal B2IO treatment. The rats which received sham treatment were treated with intraperitoneal solvent. Values are mean $\pm \mathrm{SEM}\left(\mathrm{N}=6,{ }^{*} * \mathrm{P}<0.0\right.$ I by Student's $t$-test).

Abbreviations: B210, herbal formula B210; SEM, standard error of the mean. 
demonstrated in Figure 2A. We observed that the maximal $\mathrm{P}_{\text {SOUND }}$ and the highest $\mathrm{F}_{\text {SOUND }}$ of snoring of a rat before $\mathrm{B} 210$ treatment was approximately $50 \mathrm{~dB}$ SPL and $16 \mathrm{kHz}$ individually (Figure 2Aa). After 30 minutes of B210 treatment, we observed that the maximal $P_{\text {SOUND }}$ and the highest $F_{\text {SOUND }}$ of snoring of a rat was approximately $20 \mathrm{~dB}$ SPL and $9 \mathrm{kHz}$ individually (Figure 2Ab). In Figure 2B, we quantified the relative snoring pressure and frequency of rats that received sham and B210 treatments. We found that both the relative snoring pressure and frequency in rats that received B210 treatment reduced significantly compared to those rats that received sham treatment (Figure $2 \mathrm{Ba}, \mathrm{b}, \mathrm{N}=6, P<0.01$ by Student's $t$-test).

\section{Effects of the B210 treatment on PNA and RLNA of aged rats}

An example of PNA and RLNA of a rat before and after 30 minutes of intraperitoneal B210 treatment is demonstrated in Figure 3A. PNA and RLNA of a rat obviously increased after 30 minutes of intraperitoneal B2 10 treatment. Also, the $\mathrm{T}_{\mathrm{I}}$ and $\mathrm{T}_{\mathrm{E}}$ of a rat was extended after 30 minutes of intraperitoneal B210 treatment. In Figure 3B, we quantified and then compared the relative PNA and RLNA, and we found that both the relative PNA and RLNA of rats with B210 treatment significantly increased compared to those of rats with sham treatment $(\mathrm{N}=8, P<0.01$ by Student's $t$-test). Moreover, in Figure $3 \mathrm{C}$, we quantified and then compared real $\mathrm{T}_{\mathrm{I}}$ and $\mathrm{T}_{\mathrm{E}}$ of PNA in aged rats between sham and B210 treatments, and we found that both the real $\mathrm{T}_{\mathrm{I}}$ and $\mathrm{T}_{\mathrm{E}}$ of rats with $\mathrm{B} 210$ treatment were significantly extended compared to those of rats with sham treatment $(\mathrm{N}=8, P<0.05$ by Student's $t$-test).

\section{Effects of the B210 treatment on PNA and HNA of aged rats}

An example of PNA and HNA of a rat before and after 30 minutes of intraperitoneal B210 treatment was demonstrated in Figure 4A. PNA and HNA of a rat were obviously enhanced after 30 minutes of intraperitoneal B210 treatment. Also, $\mathrm{T}_{\mathrm{I}}, \mathrm{T}_{\mathrm{E}}$, and Pre- $\mathrm{T}_{\mathrm{I}}$ of a rat were extended after 30 minutes of intraperitoneal B2 10 treatment. In Figure 4B, we quantified and then compared the relative PNA and HNA, and we found that both the relative PNA and HNA of rats with the B210 treatment were significantly increased compared to those of rats with sham treatment $(\mathrm{N}=8, P<0.01-0.05$ by Student's $t$-test). Moreover, in Figure 4C, we quantified and then compared real $T_{I}$ and $T_{E}$ of PNA, and Pre- $T_{I}$ of HNA in rats between sham and B2 10 treatments, and we found that real $T_{1}, T_{E}$, and Pre- $T_{I}$
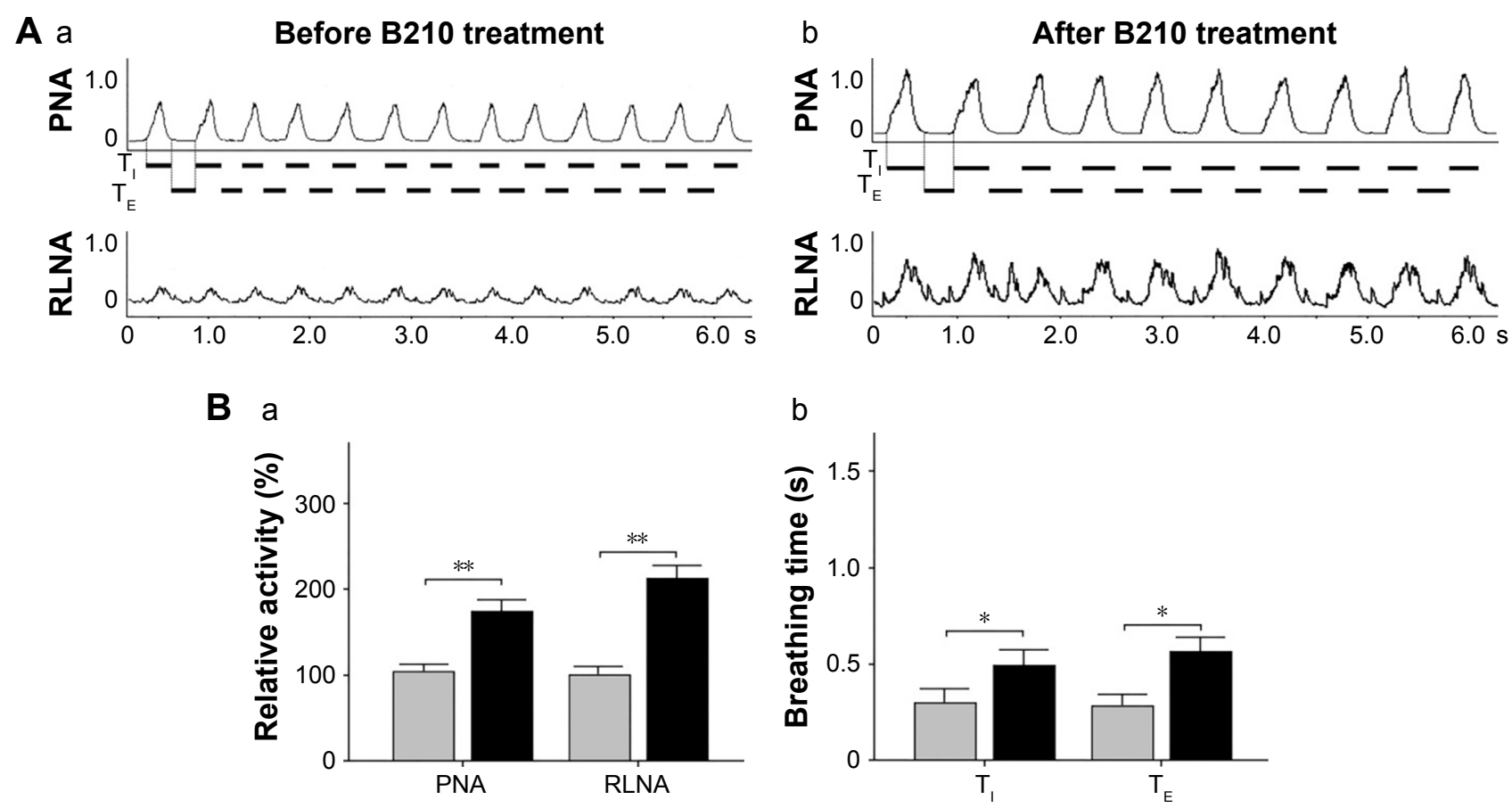

Sham

B210

Figure 3 B210 treatment significantly increased activities of phrenic and recurrent laryngeal nerves, and extended breathing time in the snoring rat model.

Notes: (A) An example of activities of phrenic nerve (PNA) and activities of recurrent laryngeal nerve (RLNA) of an aged rat before (a) and after 30 minutes of intraperitoneal B2 10 treatment (b). The scale of time is I s per grid. (B) Quantified comparison of (a) relative activities of PNA and RLNA, and (b) inspiratory time ( $\left.T_{1}\right)$ and expiratory time $\left(T_{E}\right)$ of PNA in aged rats between sham and B2 10 treatment. The rats that received sham treatment were treated with intraperitoneal solvent. Values are mean \pm SEM ( $N=8$, $* * P<0.0$ I, $* P<0.05$, by Student's $t$-test).

Abbreviations: B210, herbal formula B210; SEM, standard error of the mean. 
A a

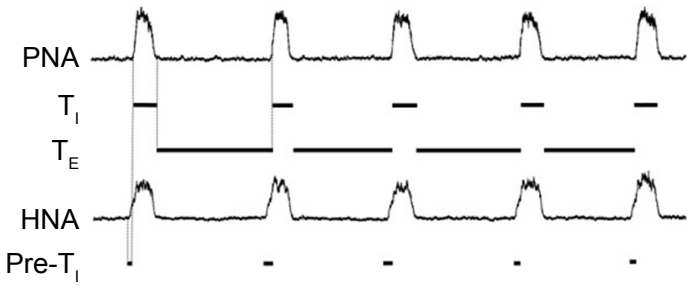

b

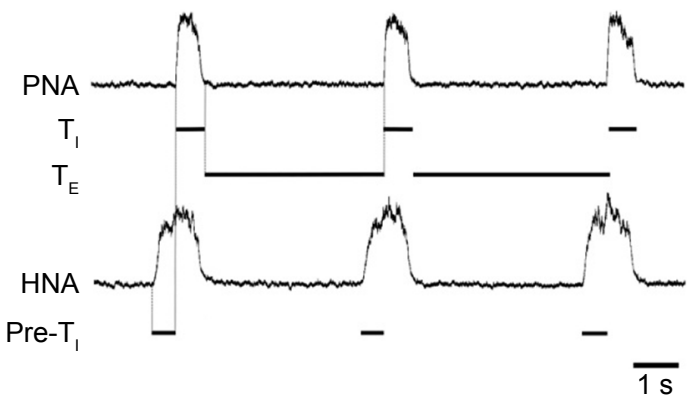

B

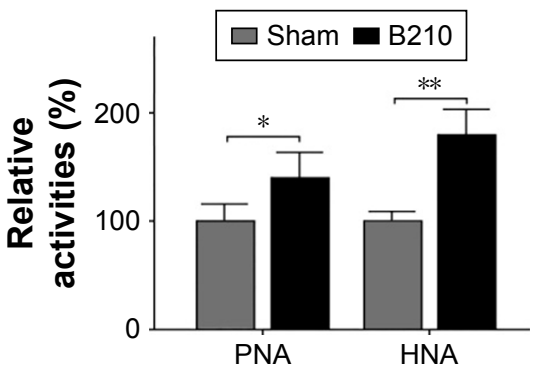

C

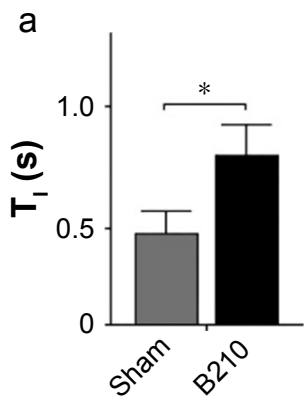

b

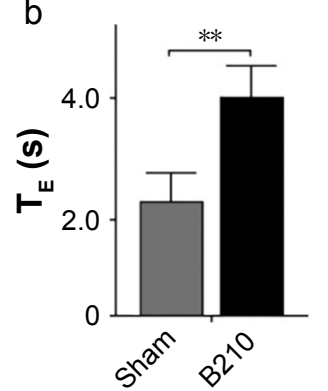

C

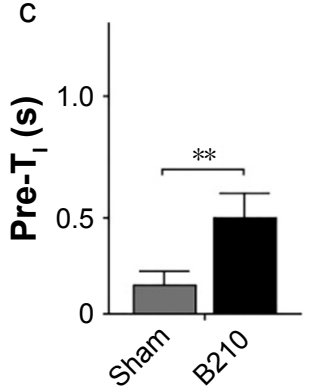

Figure 4 B2 10 treatment significantly increased activities of phrenic and hypoglossal nerves, and extended breathing time in the snoring rat model.

Notes: (A) An example of activities of phrenic nerve (PNA) and activities of hypoglossal nerve (HNA) of an aged rat before (a) and after 30 minutes of intraperitoneal B2। 0 treatment (b). (B) Quantified comparison of relative activities of PNA and HNA in aged rats between sham and B2I0 treatment. (C) Quantified comparison of (a) inspiratory time $\left(T_{1}\right)$ and $(b)$ expiratory time ( $\left.T_{E}\right)$ of PNA, and (c) pre-inspiratory time (Pre- $T_{1}$ ) of HNA in aged rats between sham and B2I0 treatment. The rats that received sham treatment were treated with intraperitoneal solvent. Values are mean $\pm \operatorname{SEM}\left(\mathrm{N}=8,{ }^{*} * P<0.0 \mathrm{I}, * \mathrm{P}<0.05\right.$, by Student's $t$-test).

Abbreviations: B210, herbal formula B210; SEM, standard error of the mean.

of rats with the $\mathrm{B} 210$ treatment were significantly extended compared to those of rats with sham treatment (Figure $4 \mathrm{C}$, $\mathrm{N}=8, P<0.01-0.05$ by Student's $t$-test).

\section{Discussion}

B210 mainly contains two kinds of medicinal herbs; $G$. elata and $C$. cassia in specific ratios. When compared to the traditional Chinese medicine, we know that none of these herbs have much therapeutic value, and to use any of them alone may prove problematic. This is the reason why we used a combined herbal formula to treat snoring in aged rats. An ingredient of B210, shown in Figure 1A, the extract of G. elata has been reported to be used for the treatment of headaches, dizziness, tetanus, and epilepsy. ${ }^{13}$ Novel pharmacological effects such as anti-angiogenic, anti-inflammatory, and analgesic activities have also been demonstrated in $G$. elata. ${ }^{14}$ Cinnamaldehyde, a major constituent of $C$. cassia, might exert anti-inflammatory and anti-depressant-like effects in aged rats when targeting the hippocampus and the frontal cortex. ${ }^{15}$ Taken together, B210 might have protective effects via reducing oxidative stress, inflammation, and depression-like effects. Furthermore, the clinical cases of more severe snoring showed great improvement after treatment with B210.

In general, snoring is caused by vibration of the soft tissues in the throat such as vocal cords and tongue.
Contraction of the posterior cricoarytenoid muscles, which are controlled by the intralaryngeal abducent branch of the RLNA, dilates the vocal cords during inspiration and reduces airflow resistance. ${ }^{16}$ In this study, we observed that aged rats had enhanced inspiratory PNA and RLNA after intraperitoneal B210 treatment (Figure 3). It has been suggested that promoting RLNA may expand vocal folds in the upper airway. This is a very reasonable explanation as to why the B210 treatment may relieve snoring through promoting RLNA and expanding vocal folds in aged rats. Also, we observed that these aged rats had extended $\mathrm{T}_{\mathrm{I}}$ and $\mathrm{T}_{\mathrm{E}}$ after intraperitoneal B210 treatment (Figure 3). Breathing time is the time taken for a single breath which consists of $T_{I}$ and $T_{E}$. These inspiration and expiration times of rats may be modified and adapted for various physical conditions and human needs. The relationships of $\mathrm{T}_{\mathrm{I}}$ and $\mathrm{T}_{\mathrm{E}}$ to end-inspiratory volume were approximately linear over the entire tidal volume range. In other words, extended $T_{I}$ and $\mathrm{T}_{\mathrm{E}}$ may enhance tidal volume of the lung. It is reasonable to postulate that the B210 treatment may enhance ventilation and relieve snoring in aged rats.

In addition to the recurrent laryngeal nerve, the hypoglossal nerve, and the intrinsic and extrinsic genioglossus also play an important role in snoring remission. The genioglossus muscle participates in a variety of motor functions 
such as phonation, swallowing, licking, mastication, and respiration. ${ }^{17-20}$ Studies in humans suggest that exercise can enhance HNA and then reduce upper airway airflow resistance during breathing. ${ }^{21}$ Respiratory-related discharge in the hypoglossal nerve is composed of pre-inspiratory and inspiratory activity. ${ }^{22}$ Pre-inspiration phase, only present in the HNA recording, corresponded to burst activity prior to the onset of PNA. By dilating the pharyngeal airway before inspiration, HNA may be particularly important in reducing upper airway airflow resistance during breathing. ${ }^{23,24}$ In this study, we observed that aged rats, after intraperitoneal B210 treatment, immediately had enhanced PNA and HNA, and prolonged Pre- $\mathrm{T}_{\mathrm{I}}$ (Figure 4). These results provide a reasonable explanation as to why $\mathrm{B} 210$ treatment in aged rats may reduce snoring, by enhancing contraction of the genioglossus.

In conclusion, we found that B210 treatment can cause upper airway patency and relieve snoring in aged rats through enhancing the upper airway related PNA, RLNA, and HNA, extending $\mathrm{T}_{\mathrm{I}}$ and $\mathrm{T}_{\mathrm{E}}$ of PNA, and prolonging Pre- $\mathrm{T}_{\mathrm{I}}$ of HNA. Thus, we suggest that $\mathrm{B} 210$ might be a potential herbal formula for snoring remission.

\section{Acknowledgments}

We thank the Brion Research Institute of Taiwan which provided our experimental materials and chromatographic fingerprint analysis of B210. This study of B210 was funded by the Brion Research Institute of Taiwan, which also owns the patent to the drug.

\section{Disclosure}

The authors report no conflicts of interest in this work.

\section{References}

1. Osorio RS, Gumb T, Pirraglia E, et al. Sleep-disordered breathing advances cognitive decline in the elderly. Neurology. 2015;84(19):1964-1971.

2. Young T, Palta M, Dempsey J, et al. The occurrence of sleep-disordered breathing among middle-aged adults. $N$ Engl J Med. 1993;328(17): $1230-1235$.

3. Young T, Finn L, Peppard PE, et al. Sleep disordered breathing and mortality: eighteen-year follow-up of the Wisconsin sleep cohort. Sleep. 2008;31(8):1071-1078.
4. Koskenvuo M, Kaprio J, Partinen M, et al. Snoring as a risk factor for hypertension and angina pectoris. Lancet. 1985;1(8434):893-896.

5. Koskenvuo M, Kaprio J, Telakivi T, et al. Snoring as a risk factor for ischaemic heart disease and stroke in men. Br Med J (Clin Res Ed). 1987; 294(6563):16-19.

6. Pengo MF, Steier J. Emerging technology: electrical stimulation in obstructive sleep apnoea. J Thorac Dis. 2015;7(8):1286-1297.

7. Chen FP, Chen TJ, Kung YY, et al. Use frequency of traditional Chinese medicine in Taiwan. BMC Health Serv Res. 2007;7:26.

8. Montserrat JM, Badia JR. Upper airway resistance syndrome. Sleep Med Rev. 1999;3(1):5-21.

9. Amatoury J, Howitt L, Wheatley JR, Avolio AP, Amis TC. Snoringrelated energy transmission to the carotid artery in rabbits. $J$ Appl Physiol (1985). 2006;100(5):1547-1553.

10. Nam H, Yang HJ, Kim YA, Kim HC. Impact of chronic simulated snoring on carotid atherosclerosis in rabbits. J Clin Neurol. 2013; 9(4):269-273.

11. Narayan J, Amatoury J, Cho JG, et al. Snoring effects on the baroreflex: an animal model. Respir Physiol Neurobiol. 2012;180(2-3):342-351.

12. Narayan J, Amatoury J, Verma M, et al. Resetting the baroreflex during snoring: role of resistive loading and intra-thoracic pressure. Respir Physiol Neurobiol. 2013;185(3):489-496.

13. Tsai CF, Huang CL, Lin YL, et al. The neuroprotective effects of an extract of Gastrodia elata. J Ethnopharmacol. 2011;138(1):119-125.

14. Ahn EK, Jeon HJ, Lim EJ, Jung HJ, Park EH. Anti-inflammatory and anti-angiogenic activities of Gastrodia elata Blume. J Ethnopharmacol. 2007;110(3):476-482.

15. Yao Y, Huang HY, Yang YX, Guo JY. Cinnamic aldehyde treatment alleviates chronic unexpected stress-induced depressive-like behaviors via targeting cyclooxygenase-2 in mid-aged rats. $J$ Ethnopharmacol. 2015;162:97-103.

16. Bartlett D Jr. Respiratory functions of the larynx. Physiol Rev. 1989;69(1):33-57.

17. Kezirian EJ, Boudewyns A, Eisele DW, et al. Electrical stimulation of the hypoglossal nerve in the treatment of obstructive sleep apnea. Sleep Med Rev. 2010;14(5):299-305.

18. Lowe AA. The neural regulation of tongue movement. Prog Neurobiol. 1980;15(4):295-344.

19. Hwang JC, St John WM, Bartlett D Jr. Respiratory-related hypoglossal nerve activity: influence of anesthetics. J Appl Physiol Respir Environ Exerc Physiol. 1983;55(3):785-792.

20. Hwang JC, St John WM. Alterations of hypoglossal motoneuronal activities during pulmonary inflations. Exp Neurol. 1987;97(3):615-625.

21. Williams JS, Janssen PL, Fuller DD, Fregosi RF. Influence of posture and breathing route on neural drive to upper airway dilator muscles during exercise. J Appl Physiol (1985). 2000;89(2):590-598.

22. Lee KZ, Fuller DD. Preinspiratory and inspiratory hypoglossal motor output during hypoxia-induced plasticity in the rat. $J$ Appl Physiol (1985). 2010;108(5):1187-1198.

23. Fukuda Y, Honda Y. Roles of vagal afferents on discharge pattern and $\mathrm{CO}_{2}$-responsiveness of efferent superior laryngeal, hypoglossal, and phrenic respiratory activities in anesthetized rats. Jpn J Physiol. 1982;32(5):689-698.

24. Sériès F, Marc I. Influence of genioglossus tonic activity on upper airway dynamics assessed by phrenic nerve stimulation. J Appl Physiol (1985). 2002;92(1):418-423.

\section{Publish your work in this journal}

Drug Design, Development and Therapy is an international, peerreviewed open-access journal that spans the spectrum of drug design and development through to clinical applications. Clinical outcomes, patient safety, and programs for the development and effective, safe, and sustained use of medicines are the features of the journal, which

\section{Dovepress}

has also been accepted for indexing on PubMed Central. The manuscript management system is completely online and includes a very quick and fair peer-review system, which is all easy to use. Visit http://www.dovepress.com/testimonials.php to read real quotes from published authors. 